\title{
Pensamiento pedagógico e ideas lingüísticas en el "Prontuario de Ortografía Práctica" (1865) de José Bernardo Suárez ${ }^{1}$
}

\author{
Natalia Valeska Villarroel Torres* \\ Universidad de Chile
}

\begin{abstract}
Resumen
El presente estudio da cuenta del análisis del Prontuario de Ortografia Práctica (1865) de José Bernardo Suárez, alumno del primer curso de la Escuela Normal de Preceptores, visitador de escuelas primarias y discípulo de D.F. Sarmiento. La investigación se enmarca en el contexto chileno de mediados del siglo XIX, aquel que propició un importante clima de debates acerca de ideas sobre lenguaje y educación, y donde se dio lugar a la reforma ortográfica chilena que intentó cambiar el paradigma impuesto por el sistema ortográfico academicista. Basándonos en la subdisciplina de la etnortografía, analizamos cómo las ideas pedagógicas y lingüísticas propuestas por Suárez se relacionaron con el contexto político y social en el que se desarrolló el proceso de estandarización lingüística de nuestro país. Este análisis nos reveló que el discurso normativo contenido en el Prontuario de Ortografía se trataba realmente de un doble discurso
\end{abstract}

\footnotetext{
1 Esta investigación forma parte del proyecto FONDECYT Regular 1150127 "Ideas lingüísticas en los debates sobre léxico y ortografía en Chile (1875-1927)" (investigador responsable: Darío Rojas).

* Para correspondencia, dirigirse a: Natalia Valeska Villarroel Torres (n.villarroeltorres@ gmail.com), Facultad de Filosofía y Humanidades, Departamento de Lingüística, Universidad de Chile. Av. Capitán Ignacio Carrera Pinto 1025, Ñuñoa, Santiago, Chile.
} 
que, mediante las prácticas pedagógicas adoptadas por Suárez en su manual, articuló simultáneamente un discurso lingüístico y un discurso político-social que reflejaban las ideologías del contexto chileno del siglo XIX.

Palabras clave: manuales de ortografía, reforma ortográfica chilena, etnortografía, ideas pedagógicas, ideas lingüísticas, estandarización lingüística.

\title{
Pedagogical and linguistic ideas in José Bernardo SuÁrez's "Prontuario de ortografía PrÁCticA" (1865)
}

\begin{abstract}
This paper presents the analysis of the Prontuario de Ortografia Práctica (1865), written by José Bernardo Suárez, student of the first course of the Normal School of Teachers, inspector of primary schools and pupil of D. F. Sarmiento. The research is part of the mid-nineteenth century Chilean context, which created a climate of important debates about language and education ideas, and which carried out the Chilean spelling reform that tried to change the paradigm imposed by the academic orthography. This research is based on the subdiscipline of ethnorthography. Here we analyze how the pedagogical and linguistic ideas proposed by Suarez are related to the political and social context, in which was developed the process of linguistic standardization in our country. The analysis reveals that the normative discourse contained in the spelling manual, actually is a double speech that simultaneously articulated both linguistic and social-political discourses, through pedagogical practices adopted by Suarez in his manual. Therefore, they reflect the ideologies of the nineteenth century Chilean context.
\end{abstract}

Keywords: spelling manuals, chilean spelling reform, ethnorthography, pedagogical ideas, linguistic ideas, linguistic standardization.

Recibido: $07 / 03 / 2016 \quad$ Aceptado: 28/10/2016

\section{INTRODUCCIÓN}

Los estudios que se han realizado en torno a la situación independentista chilena en el siglo XIX, sobre ideologías, actitudes y sobre el proceso de 
estandarización de la lengua, han dado preferencia al estudio de gramáticas y diccionarios (Calero Vaquera 2010), concibiendo a este tipo de herramientas estandarizadoras como productos culturales. Sin embargo, en cuanto al aspecto ortográfico no podemos decir lo mismo.

A pesar de que se ha descrito y estudiado la situación del reformismo en la ortografía, no se ha prestado la misma atención al estudio de los manuales ortográficos, por lo que el análisis acerca del contenido ideológico que puede ofrecernos este tipo de herramientas aún es un campo poco explorado.

En esta oportunidad dicho argumento ha sido la motivación para iniciar un estudio que, además de hacerse cargo del contenido que presenta este tipo de documentos, nos permita indagar en la naturaleza de los mismos y rescatar ciertos recursos que podrían servirnos para encontrar e interpretar ideas que se generaron en torno al lenguaje en el proceso estandarizador chileno.

Para ello estudiaremos un manual de ortografía que formó parte de las herramientas alfabetizadoras utilizadas en la educación primaria del siglo XIX. Con esto nos referimos al Prontuario de Ortografía Práctica (1865) de José Bernardo Suárez, el primer preceptor chileno de educación primaria, quien además fue discípulo de Domingo Faustino Sarmiento.

De tal forma, y considerando que este documento corresponde a la reedición de un manual de ortografía publicado por Suárez en 1858, el Prontuario de Ortografía Castellana, pretendemos realizar un estudio metadiscursivo que nos permita analizar el contexto en el que nuestro objeto de estudio fue elaborado y reeditado.

Para estos efectos, nos serviremos del concepto de etnortografia (Calero Vaquera 2010), una subdisciplina de la glotopolítica ${ }^{2}$ que se dedica a analizar en profundidad cómo las ideologías lingüísticas ${ }^{3}$-entendiéndolas como “[...] el conjunto de creencias, sentimientos y concepciones sobre la estructura y el uso del lenguaje, las que a menudo responden a los intereses políticos y económicos de hablantes individuales, a grupos sociales determinados y a estados nacionales" [Traducción propia] (2010: 192)-de un tiempo y lugar determinado pueden ser representadas en manuales de ortografía, dado que estos instrumentos de estandarización también permiten traducir ciertas marcas de la lengua escrita como señales de identidad de las sociedades.

\footnotetext{
2 La glotopolítica se entiende, según plantean Guespin y Marcellesi (1986), como algo "[...] necesario para abarcar todos los hechos del lenguaje en los que la acción de la sociedad reviste la forma de lo político" (cit. en Del Valle 2014: 88).

3 En palabras de Del Valle las ideologías lingüísticas son "sistemas de ideas que articulan nociones sobre el lenguaje, las lenguas, el habla y/o la comunicación con formaciones culturales, políticas y/o sociales específicas" (2007: 20).
} 
Además, creemos que estudiar el discurso contenido en un manual de ortografía que se elaboró en medio de una situación de reforma o revolución ortográfica (Sebba 2007), como fue el caso de nuestro país, sería el momento más idóneo para analizar las ideologías políticas, culturales y religiosas de una comunidad (Velleman 2014), pues en este tipo de escenario, además de originarse un debate lingüístico, podemos hallar una competencia de discursos en la que "un discurso educacional es a menudo relacionado con un discurso de reforma social" [Traducción propia] (Sebba 2007: 151).

De acuerdo con todo lo anterior, la presente investigación analizará las ideas pedagógicas y lingüísticas que se encuentran contenidas, implícita o explícitamente, en el discurso articulado por José Bernardo Suárez en la reedición de su manual de ortografía. Para cumplir este objetivo, por un lado, buscamos identificar ciertos mecanismos o expresiones que puedan manifestar las ideas pedagógicas y lingüísticas adoptadas por Suárez, y por otro, describir cómo operan estos recursos hallados, en relación con el contexto político y social del siglo XIX, aquel donde se desarrolló el proceso de estandarización lingüística de nuestro país.

En definitiva, consideramos que una investigación de estas características contribuiría al conocimiento de los manuales de ortografía como instrumentos lingüísticos que trabajan en sintonía con el contexto histórico y cultural de las comunidades. Así como también podríamos aportar conocimientos acerca del contenido y la estructura de los manuales de ortografía chilenos, mediante el análisis de los recursos y mecanismos lingüísticos que se encuentran contenidos dentro del discurso ortográfico.

\section{ANTECEDENTES Y CONTEXTO CHILENO EN EL SIGLO XIX}

Nuestro estudio se inserta en el escenario político, social y cultural que vivió Chile a mediados del siglo XIX, aquel contexto en el que se estaba afianzando una serie de procesos políticos que surgieron tras la independencia de Chile y gran parte de las naciones de Hispanoamérica.

La tarea de construcción de la nación en el Chile postindependentista fue desempeñada principalmente por la elite ilustrada de nuestro país, aquella que primero se identificó con un naciente americanismo que rechazaba lo hispánico, y que luego dio marcha a la afirmación de lo nacional por medio de "la regeneración de las costumbres y la búsqueda de lo propio" (Subercaseaux 2010: 315). 
En este proceso, el aspecto lingüístico fue crucial. Junto a las discusiones políticas los intelectuales de la época desarrollaron diversos debates acerca del lenguaje, a partir de los cuales surge un proceso de estandarización lingüística ${ }^{4}$ (Haugen 1966) o estandarización circunstanciada, como mencionan Matus, Dargham y Samaniego (1992), donde la variedad hablada o vernácula del español de Chile se transformó en una lengua activa (Bravo 2010) o, en otras palabras, en una lengua nacional con su propia historia (Metzeltin 2011).

Esta situación permitió expresar abiertamente cómo el lenguaje era negociado y articulado por medio de una serie de normas lingüísticas (Lara 1976), lo que a su vez propició la elaboración de instrumentos estandarizadores, la regulación de los sistemas de escritura y la implementación de un sistema educativo que permitió el acceso a la escolaridad y a la alfabetización (Arnoux 2008).

\subsection{LA REFORMA ORTOGRÁFICA CHILENA}

En este escenario de cambios sociales, culturales y económicos tuvo lugar la reforma ortográfica chilena, aquella que surge en los primeros años de la década de 1840 y que estuvo asociada a tres importantes sucesos, a saber, la fundación del Instituto Nacional (1813) y las fundaciones de la Escuela Normal de Preceptores y de la Universidad de Chile en 1842. Todos ellos hitos ocurridos producto de la atención que se prestó al cultivo de la educación con el fin de desarrollar y consolidar la república chilena.

Del mismo modo como ocurrió en otras zonas de Hispanoamérica, la reforma ortográfica chilena buscaba afirmar la identidad de la nación destacando las particularidades de la lengua española americana en relación con el español de la metrópolis (Serrano, Ponce de León y Rengifo 2012). Por ende, el aspecto ortográfico del lenguaje se concibió, por parte del Estado, como un modo de reestructuración social del pueblo chileno.

Las figuras que participaron de forma más activa en lo que duró la reforma ortográfica fueron don Andrés Bello (1781-1865) y el argentino Domingo Faustino Sarmiento (1811-1888), quienes representaron las dos propuestas

\footnotetext{
$4 \quad$ El modelo de estandarización lingüística de Haugen (1966) plantea cuatro fases que debe atravesar una lengua para que logre uniformarse: 1) la selección de la norma; 2) la codificación de la forma; 3) la elaboración de la función, y 4) la aceptación por parte de la comunidad para que la norma seleccionada, codificada y elaborada pueda utilizarse.
} 
ortográficas más decisivas en los tiempos de la reforma. Ambos autores, aunque desde perspectivas distintas, dieron origen a una polémica ortográfica en que criticaron el sistema de escritura academicista y abogaron por un cambio en las reglas ortográficas basado en la pronunciación ${ }^{5}$ del sistema de lengua americano. Es decir, por un sistema biunívoco entre fonema y grafema que hiciera posible la cohesión del idioma y la simplificación de la enseñanza y aprendizaje de la lectoescritura.

La preocupación ortográfica que Bello planteó en sus Indicaciones sobre la conveniencia de simplificar i uniformar la ortografía en América en 1823, marcó el precedente para el debate acerca del tema ortográfico en Chile. Pero la reforma, propiamente tal, se inició con las labores realizadas por Sarmiento en el ámbito educacional, específicamente cuando el ministro de Instrucción Pública, Manuel Montt, lo designa director de la Escuela Normal de Preceptores y le encomienda un estudio sobre los métodos de lectura y alfabetización utilizados en Chile.

Tal situación permite que el argentino saque sus propias conclusiones acerca de las falencias del sistema ortográfico español, las que posteriormente decide plasmar a modo de propuesta en la publicación de su Memoria, un documento que presentó en 1843 en la Facultad de Humanidades de la Universidad de Chile de la cual él era miembro.

La publicación de la Memoria fue el hito que abrió el debate lingüístico, ya que al proponer un alfabeto basado en las particularidades de la pronunciación americana, además de buscar la simplificación de la adquisición y utilización de la ortografía en la educación, desautorizó el antiguo alfabeto implantado por la academia.

El enfoque de la propuesta de Sarmiento era romántico, según Torrejón (1989), y radical y dirigista, según Arnoux (2006), ya que buscaba imponer una norma lingüística en todos los ámbitos de uso del lenguaje, es decir, en la educación, la prensa y la literatura. Al exigir el cumplimiento de su propuesta, Sarmiento señala su creencia de que para establecer o hacer funcionar una medida glotopolítica en las sociedades modernas y que esta resulte exitosa, dicha medida "debe ser sancionada por una autoridad competente que legitime las prácticas y las imponga en el aparato estatal" (Arnoux 2006: 52).

\footnotetext{
5 En otras palabras, lo que se quiso hacer fue adaptar el sistema ortográfico de la Academia, aquel que estaba compuesto por tres principios: 1) el etimológico; 2) el de uso constante, y 3) el de pronunciación, por uno que se basara solamente en este último. Sarmiento se refiere en su Memoria (1843) a estos tres principios utilizados por la Real Academia Española, los que denomina bajo el concepto de trinidad tiránica.
} 
Sin embargo, el tono beligerante de la propuesta de Sarmiento hizo que en 1844, un año después de la publicación de su Memoria, la Comisión de la Facultad de Humanidades de la Universidad de Chile rechazara su propuesta ortográfica y, a cambio de esta, se pronunciara con una nueva que proponía un cambio gradual de la ortografía en Chile.

El principal impulsor de esta nueva propuesta fue Andrés Bello, quien a pesar de mantener un enfoque clasicista de la lengua - a partir del que se observaba una "extrema lealtad hacia una norma lingüística panhispánica basada en los escritos clásicos y de los más cuidados estilistas españoles de los siglos XVII y XVIII" (Torrejón 1989: 542) - propuso una reforma ortográfica progresiva fundada en la pronunciación americana que, a diferencia de la propuesta de Sarmiento, instaba a los intelectuales de la época a la discusión. Por lo tanto, el venezolano no exigió el cumplimiento de su reforma, solo la planteó como una sugerencia que debía ser discutida antes de ser impuesta (Arnoux 2006).

A pesar de que Bello y Sarmiento distaron en cuanto al enfoque de sus posturas, varios de sus planteamientos ortográficos estaban en consonancia, pues para ambos intelectuales la reforma de la ortografía era, por un parte, "la forma de enfrentar el desorden generado por la coexistencia de tres principios contradictorios" (Arnoux 2006: 49), y por otra, la de simplificar y democratizar la enseñanza y civilización del pueblo chileno.

En este panorama de la reforma cabe destacar que, si bien Bello y Sarmiento representaron las dos propuestas ortográficas más decisivas de la época, el desarrollo del debate ortográfico no solo se llevó a cabo por estas dos figuras. Otros intelectuales también participaron del debate lingüístico creando un clima polémico mediante ataques y contraataques ideológicos publicados en la prensa de la época, situación que se vivió durante varios años.

Dicho panorama desembocó en lo que Contreras (1993) denominó como caos ortográfico, momento donde se lograron identificar varios estados o tipos de ortografía ${ }^{6}$, dado que cada usuario utilizaba la norma ortográfica que más le acomodaba. En este sentido, la polémica ortográfica produjo

\footnotetext{
6 En el periodo de reforma se pueden distinguir tres tipos de ortografía: la ortografía reformada, aquella que fue propuesta por la Universidad de Chile en 1844; la ortografía de Bello, que en estricto rigor no era de Bello, puesto que se reducía a solo dos de los rasgos propuestos por él (la utilización de $j$ en lugar de $g$ y de $i$ en lugar de $y$ ), y la ortografía chilena, que correspondía a los rasgos de la reforma de la Universidad de Chile que se mantuvieron más tiempo vigentes, es decir, la utilización de $i$ en lugar de $y$, de $j$ en lugar de $g$ y de $s$ en lugar de $x$ (Angel Rosemblat 1951, cit. en Arnoux 2008).
} 
constantes disidencias por parte de los intelectuales y una gran confusión acerca de cuál era la norma que debía utilizarse.

Así, esta situación de polémicas y caos culminó con la decadencia de la reforma propuesta por la Universidad de Chile en 1844 debido a "[...] un mandato presidencial en 1927, en el que, por decreto, se instituía la ortografía de la Real Academia de la Lengua como oficial y de uso obligatorio en Chile (Contreras 1993: 14).

\subsection{LA REFORMA EDUCATIVA CHILENA EN EL SIGLO XIX}

Paralelamente, el clima de debates lingüísticos que se vivió en el siglo XIX, tanto en torno a la ortografía como a otros aspectos del lenguaje, fue acompañado de un proceso simultáneo que puso en marcha el desarrollo de un plan educativo integral dirigido hacia gran parte de la población de nuestro país.

Luego del desprendimiento político e institucional de España, la nación chilena busca nuevos referentes en el ámbito político y social, así como también en el educacional. "La vertiente ideológica y dominante que recrea este nuevo universo simbólico lo constituye sin duda la ilustración" (Conejeros 1999: 18), el movimiento cultural e intelectual europeo que garantizaba el acceso al progreso y al bienestar de las naciones.

Los ideales ilustrados provenientes desde Francia son los que influyeron en el nuevo pensamiento educacional chileno inculcando la importancia del aprendizaje de un saber laico, basado en la razón, que ampliara el universo de conocimientos a partir de la premisa "libertad, igualdad y fraternidad".

Figuras de la nueva elite criolla chilena como Andrés Bello, D. F. Sarmiento, José Victorino Lastarria, Ignacio Domeyko, los hermanos Amunátegui, entre otros, fueron los encargados de realizar la tarea de adquisición y difusión de estos ideales franceses, en especial los tres primeros, quienes fueron considerados como "los grandes inspiradores" de los ideales europeos en tierra chilena (Labarca 1939: 103), sobre todo en el ámbito educativo.

De los tres, Sarmiento fue quien mostró una mayor preocupación por este aspecto, pues se dedicó a dar cuenta de las falencias del sistema educativo y a promover el aprendizaje en todos los sectores de la población chilena, a partir de la idea de que la educación abría las puertas de la civilización al pueblo (Valdivia Castro 1933). El argentino ofreció en sus numerosos trabajos y publicaciones en prensa algunas formas para la superación de los problemas que acaecieron en el sistema educativo de nuestro país, y 
además, se preocupó de instaurar una enseñanza metódica de la lectura y la escritura, de guiar el trabajo de los alumnos en el aula y de instruir a los maestros en su quehacer pedagógico.

\subsection{Pensamiento y obra de José Bernardo Suárez}

Para efectuar esta ardua labor educativa, Sarmiento aleccionó a varios maestros en la Escuela Normal de Preceptores Primarios. De sus aprendices, destacó el trabajo desarrollado por su discípulo, amigo y colaborador, José Bernardo Suárez, el primer educador formado en dicha escuela.

Suárez se mantuvo cincuenta y seis años al servicio de la educación (Salas 2010), camino que recorrió cumpliendo diversas funciones que aportaron a mejorar las formas de enseñanza y aprendizaje de nuestro sistema educativo.

El preceptor primario destacó desde un comienzo en sus labores pedagógicas, ya que desde el momento en que el gobierno lo nombró visitador de escuelas ${ }^{7}$ demostró un gran interés por la mejora del sistema educativo realizando informes en los que se corregían deficiencias y se apuntaban conclusiones acerca del estado en el que se encontraba la educación en cada uno de los establecimientos educacionales del país (Valdivia Castro 1933), de modo que no fue un simple visitador de escuelas, sino que "[...] el más notable de ellos" (Labarca 1939: 123).

Asimismo, Suárez impulsó la creación de centros de formación de profesores, bibliotecas y una gran variedad de textos que sirvieron como material para el aprendizaje de la lectura y la escritura, tanto en Chile como en otras zonas de Hispanoamérica.

Siguiendo esta línea, la labor pedagógica de Suárez lo lleva a elaborar en 1865 el Prontuario de Ortografía Práctica, objeto de análisis de nuestra investigación. Para su elaboración, Suárez recurre a obras ortográficas como

7 La Ley de Instrucción pública chilena de 1860 decretó en varios de sus artículos ciertas disposiciones que establecieron cuáles debían ser las tareas desarrolladas para llevar a cabo la labor de inspección de la educación, así como también, quiénes eran los agentes encargados de concretar dichas labores. Así, en el pertinente trabajo de Manuel E. Ballesteros, "Compilación de Leyes i Decretos Vijentes en materia de Instruccion Pública" (1872), nos es posible observar que en la Ley de 1860 se decretaron resoluciones como las siguientes: "Art. 25. Habrá una inspeccion que vijile i dirija la instruccion primaria en toda la República; Art. 26. Esta inspeccion se compondrá de un inspector jeneral i de un visitador de escuelas para cada una de las provincias del Estado; Art. 27. El inspector jeneral será nombrado por el Presidente de la República. Igualmente los visitadores de escuelas, a propuesta del inspector jeneral [...]" (Manuel E. Ballesteros 1872: 271). 
las de Bello, Salvá y Fernández Monje, entre otras, pero resalta por sobre todas ellas la obra de Fco. Vargas Fontecilla, Lecciones de Ortografia Castellana (1854 [1857]). Según Suárez, este compendio de reglas ortográficas habría sido el mejor y más ejemplar manual de ortografía elaborado hasta entonces en nuestro país, ya que exponía con fidelidad el uso general de la ortografía en Chile sin adherirse a ningún sistema ortográfico en particular.

Contreras (1993) afirma que, del mismo modo que el manual de Vargas Fontecilla, el Prontuario de Ortografía Práctica de Suárez favoreció la mantención de una cierta estabilidad de lo que se conoció como ortografía chilena u ortografía casera. Hecho que se debe seguramente a que Suárez, por un lado, se dejó influir por planteamientos como el de Vargas Fontecilla y demás autores, y por otro, debido a que adquirió una postura ortográfica distinta a la de Sarmiento, una no tan radical ni directiva como la de su mentor.

A pesar de esto, el manual ortográfico de Suárez demostró que sus pensamientos pedagógicos estaban en completa consonancia con los planteados anteriormente por Sarmiento, dado que dentro de su obra se encuentra constantemente exponiendo la idea de que la escuela y la educación eran las herramientas clave que propiciaban la civilización y el desarrollo del pueblo.

\section{LAS FUENTES DE ESTUDIO}

Como mencionamos anteriormente, nuestra investigación está orientada hacia el análisis de las ideas lingüísticas y pedagógicas del Prontuario de Ortografía Práctica (1865) de José Bernardo Suárez, documento que corresponde a la reedición de un trabajo publicado previamente por el mismo autor en 1858, el Prontuario de Ortografia Castellana.

Al ser un documento correlato del otro, nos parece pertinente ahondar en los detalles que fueron modificados durante los siete años que separan a ambas publicaciones, pues esto nos permitirá ampliar el análisis de la obra ortográfica de Suárez y observar más de cerca su pensamiento pedagógico.

De acuerdo con esto, es importante mencionar que la sección de presentación del Prontuario de 1865 no solo consta de la reproducción de la presentación del Prontuario de 1858, sino que además expone y comenta cuáles son las novedades que trae esta nueva edición, vale decir, los elementos o ítems que han sido agregados, suprimidos o modificados. 
De este modo, nos enteramos de que en el Prontuario de Ortografía Práctica:

i. Se han suprimido los vocabularios de palabras de dudosa ortografía ${ }^{8}$ que contenía el primer Prontuario.

ii. Se ha aumentado la cantidad de ejemplos a lo largo de todo el manual.

iii. Y se han agregado o integrado ejercicios para la pizarra, recomendaciones para los maestros, un apéndice sobre nociones gramaticales, y una sección de advertencias sobre el uso de la lengua castellana dirigida a los niños, padres y maestros.

Sumado a esto, la reedición trae una dedicatoria dirigida a Domingo F. Sarmiento y una breve referencia titulada Aprobación Universitaria, secciones que también revisaremos en esta oportunidad.

Finalmente, indicamos que por razones de extensión y debido a las reiteradas veces en que hacemos alusión a los dos manuales ortográficos de Suárez, hemos decidido abreviar los nombres de la $1^{\circ}$ y $2^{\circ}$ edición de la siguiente manera: Prontuario de Ortografía Castellana (P1) y Prontuario de Ortografía Práctica (P2), lo que nos permitirá presentar de manera más clara y sucinta los datos de este estudio.

\section{SOBRE LA DEDICATORIA Y LA APROBACIÓN UNIVERSITARIA}

En las primeras páginas del Prontuario de Ortografía Práctica nos encontramos con la dedicatoria del manual y un breve texto titulado Aprobación Universitaria, dos secciones que nos revelan algunos aspectos del pensamiento pedagógico de Suárez y ciertas instancias o intervenciones políticas que estuvieron involucradas en la confección y difusión del P2.

\footnotetext{
8 Se trataban de largos inventarios de palabras, nombres y apellidos ordenados alfabéticamente, donde se hallaban voces que generalmente eran objeto de errores o dudas al momento de ser escritas. Si bien dicho recurso fue eliminado por Suárez en el Prontuario de 1865, esta información no fue completamente olvidada, pues el autor introdujo fragmentos de estos vocabularios en la reedición, pero ahora como ejemplos que acompañaban al cuerpo del texto. De esta manera, se siguen exponiendo ciertas palabras que, según Suárez, requerían de mayor empleo y revisión para que la memoria se acostumbrase a su uso.
} 
A diferencia del documento de 1858 que estuvo dedicado brevemente a "Don Miguel Sevilla" - un buen amigo y colaborador de Suárez, quien lo auxilió en temas relativos a la enseñanza de la educación primaria en instancias vividas en Santiago y en labores realizadas en Chiloé - la dedicatoria contenida en el P2 estaba dirigida a don Domingo F. Sarmiento, quien como bien sabemos fue maestro de Suárez e impulsor de su carrera preceptora. De ahí que encontremos una concordancia inmediata entre el destinatario de la dedicatoria y el especial agradecimiento con el que está escrita.

SEÑOR DON DOMINGO F. SARMIENTO,

Ministro plenipotenciario de la República Arjentina, etc., etc.

Lima.

Santiago de Chile, 15 de Febrero de 1865.

Señor de todo mi aprecio i respeto:

A Ud. que, en 1842, me hizo maestro de escuela i me trazó el camino de la dignidad i del decoro, que jamás he abandonado,

debo dedicarle el escaso fruto de mis observaciones en la enseñanza de la Gramática Castellana, el cual se halla contenido en el presente opúsculo ${ }^{9}$. Sírvase, pues, aceptarlo con la benevolencia que le es propia, como una débil muestra del afecto que le profesa su S.S.

\section{J. B. SUÁREZ.}

Si observamos en detalle la dedicatoria podremos percataremos, ya en el fragmento destacado, que la relación entre Suárez y Sarmiento resultó bastante influyente en el desempeño del preceptor primario, pues al presentar Suárez su Prontuario reeditado como el producto de un arduo trabajo de observaciones en el área de la Gramática Castellana, el autor está expresando que su interés era abordar todos los puntos problemáticos que aquejaban a la enseñanza del castellano, tanto gramatical como ortográficamente ${ }^{10}$. Este hecho nos permite ver cómo Suárez desempeñó su labor pedagógica del mismo modo que Sarmiento, pues el proceso previo a la elaboración

\footnotetext{
9 El destacado de este fragmento y del resto de los fragmentos a los que recurrimos para ejemplificar en esta investigación, son nuestros.

10 La idea que se desprende de la dedicatoria del P2 puede complementarse con el hecho de que en este mismo documento se anexa una sección a modo de apéndice (pág. 42) sobre nociones gramaticales, materia que si bien escapa a lo que ofrecería un manual de ortografía propiamente tal, demuestra por otro lado la entereza de Suárez al querer dar cuenta de otros puntos problemáticos de la lengua en la educación primaria.
} 
de su manual ortográfico es similar al que vivió Sarmiento al publicar su Memoria (1843).

De esta manera, ambos autores a partir de su trabajo pedagógico evaluaron la situación lingüística chilena y convirtieron sus observaciones en instrumentos estandarizadores de la lengua, de modo que los textos de enseñanza estuvieran en directa relación con las demandas de los preceptores en el aula (Serrano et al. 2012). Este procedimiento refleja la preocupación por la educación que circulaba en la época, ya que ahora eran maestros los que se preocupaban del quehacer lingüístico y que apoyaban al Estado en la formación de ciudadanos en las escuelas públicas.

Ahora bien, más allá del vínculo existente entre Suárez y Sarmiento, podemos pensar que la dedicatoria del P1 al P2 cambia, también, debido a que Sarmiento era miembro fundador de la Facultad de Humanidades de la Universidad de Chile, entidad que según el artículo $1^{\circ}$ de la Ley orgánica instituida por el Congreso Nacional, era la encargada de velar por la educación chilena en todos sus aspectos:

"Habrá un cuerpo encargado de la enseñanza i el cultivo de las letras i ciencias en Chile. Tendrá el título de Universidad de Chile. Corresponde a este cuerpo la dirección de los establecimientos literarios i científicos nacionales, i la inspeccion sobre todos los demas establecimientos de educacion" (Ballesteros 1872: 2).

En este sentido, estamos planteado que Sarmiento aparece en la reedición del trabajo de Suárez, también, a modo de autoridad. Asimismo como encontramos a Bello firmando en la Aprobación Universitaria, sección que dentro del P2 sucede a la dedicatoria.

\section{APROBACIÓN UNIVERSITARIA.}

Santiago, Mayo 2 de 1865.

Conforme a lo acordado por el Consejo en sesion de 29 de Abril último a virtud del informe que precede, apruébase para texto de enseñanza en las escuelas primarias el PRONTUARIO DE ORTOGRAFÍA PRÁCTICA, escrito por don José Bernardo Suárez.

Anótese.

ANDRÉS BELLO.

Miguel L. Amunátegui,

Secretario Jeneral

A diferencia de la dedicatoria, este breve apartado corresponde a una declaración, o una suerte de sello de calidad, con la que se otorga validez a 
la reedición de Suárez por parte del Consejo Universitario de la Universidad de Chile ${ }^{11}$. A partir de la integración de este recurso en el P2, no solo se hace visible la intervención de un organismo tan importante como la Universidad, o la participación de la figura patronímica de Andrés Bello, sino que también la participación del sector político chileno en asuntos educativos.

Esto queda más claro si nos remitimos a la Ley Orgánica de Instrucción Pública que se promulgó en nuestro país en 1860. En ella, el artículo $94^{\circ}$ establece con claridad que la sección de Aprobación Universitaria que encontramos en el P2 no sería un elemento introducido al azar en el manual de Suárez, pues se menciona que "[e]n las escuelas públicas de instrucción primaria no se enseñará por otros textos i libros que los que hubieren sido aprobados por la Universidad i mandados adoptar por el Gobierno" (Ballesteros 1872: 287).

De este modo, las estrategias políticas que están detrás de la elaboración, publicación y difusión de herramientas estandarizadoras de la lengua en la enseñanza del siglo XIX nos revelan que Suárez reeditó su trabajo ortográfico principalmente para que este estuviera vigente y cumpliera todas las normas que la ley le imponía, de otro modo no podría haber efectuado su labor educativa.

\section{EL DISCURSO NORMATIVO DE LOS PRONTUARIOS DE ORTOGRAFÍA: TEMÁTICAS DE ADOCTRINAMIENTO}

El cuerpo del texto del P2, del mismo modo que el P1, está constituido por tres grandes apartados que contienen toda la información o contenido ortográfico. Estos son los apartados de: i) Letras; ii) Acentuación, y iii) Puntuación, los que están estructurados de acuerdo con un listado o conjunto de reglas que indican cómo se rige el sistema de escritura de la lengua española en cada uno de sus aspectos.

Gracias a los comentarios que Suárez realiza en la presentación del P2, hemos podido observar la existencia de algunas modificaciones que el autor ha realizado en torno a estos tres apartados, desde la publicación del

11 La Aprobación Universitaria aparece firmada por don Andrés Bello y Miguel Luis Amunátegui, quienes eran director y secretario general del Consejo Universitario en ese entonces. 
P1 al P2 (Véase el apartado $\mathrm{N}^{\circ} 3$ ), con el objetivo de hacer más accesible la adquisición y el afianzamiento de los contenidos ortográficos.

Si nos percatamos, la mayor parte de estas modificaciones se ha realizado en el plano de los recursos paratextuales que acompañan al cuerpo del texto, los que en este caso corresponden a: ejemplos, citas, notas a pie de página, ejercicios para la pizarra, e incluso a recursos como la presentación, la dedicatoria, las advertencias y el apéndice.

El hecho de que este tipo de recursos se hallen interactuando constantemente con las reglas o contenido ortográfico dentro de los Prontuarios, nos ha permitido observar cómo José Bernardo Suárez construye en sus manuales de ortografía lo que, en palabras de Arnoux (2008), sería el discurso normativo.

Según hemos podido identificar, el discurso normativo construido por Suárez corresponde realmente a un doble discurso donde se entraman aspectos lingüísticos y aspectos del contexto de producción de los Prontuarios de ortografía, es decir, de acuerdo con un discurso lingüístico y un discurso político-social, como los hemos denominado.

El discurso lingüístico trata sobre el lenguaje y se encarga de instruir acerca de ideas ortográficas y gramaticales con la finalidad de alcanzar la unificación de las prácticas lingüísticas de la sociedad.

En cambio, el discurso político-social, si bien se enlaza con el anterior, persigue fines más ambiciosos, ya que a través de la unificación lingüística pretendía educar sobre asuntos políticos, sociales y culturales que contribuían al proceso de consolidación del Estado y la nación chilena.

En este sentido, se entiende que el discurso lingüístico se encuentra operando sobre un discurso político-social, situación que da cuenta de un universo ideológico que va más allá del universo del lenguaje.

Dicho de otro modo, los Prontuarios de ortografía corresponden a herramientas estandarizadoras que generaron un proceso de adoctrinamiento dirigido principalmente a niños, el que se realizó mediante prácticas pedagógicas que permitieron la operatividad del lenguaje (Arnoux y Del Valle 2010) sobre un contexto político, social y cultural en el que se pretendía alcanzar la unificación lingüística y la consolidación del Estado y la nación.

\subsection{DisCuRSO LINGÜístico}

En el Prontuario de Ortografía Práctica el discurso lingüístico da cuenta de una idea o de un modelo de lengua que se pretendía instaurar para lograr la unificación de las prácticas lingüísticas de la comunidad chilena. 
Por una parte, esto se puede observar desde el trato que reciben las reglas o contenido ortográfico en el cuerpo del texto, puesto que los tres grandes apartados que dividen tanto al P1 como al P2, al exponer información acerca de las letras, la acentuación y la pronunciación del español de Chile, daban cuenta de una propuesta ortográfica que era válida para esa época.

Un ejemplo de esto podemos observarlo en el primer apartado común a ambos Prontuarios, donde se trata el uso correcto de las letras del alfabeto español en Chile. Allí el autor afirma que el sistema ortográfico que él utiliza en su manual se basa en el principio de pronunciación, puesto que la mayoría de las letras de nuestro alfabeto se escriben correctamente guiándose por el sonido.

A pesar de ello, Suárez menciona la existencia de algunas letras que tienden a confundirse y a ser fuentes comunes de error, tales como: $b, v$, $c, s, z, g, j, y, h, l l, r$ y $x$, por lo que propone el uso de otro criterio para solucionar aquellas vacilaciones por parte del usuario al momento de escribir. Así, Suárez plantea como solución el principio de uso constante, aquel donde se consideran correctos los usos que son más utilizados y, por ende, convenidos por la comunidad. Este hecho que aparece expresado ya en el $\mathrm{P} 1^{12}$-cuando el autor afirma que: "[e]ste principio es el que debe guiarnos, cuando la pronunciación no determina las letras con que hemos de escribir" (Suárez 1858: 8)- nos indica cómo Suárez, al igual que Vargas Fontecilla (1854 [1857]), no opta por ninguna reforma ortográfica en particular, sino que se limita a entregar un compendio de reglas que describen el estado de la ortografía chilena de ese entonces, o lo que en palabras de autores como Contreras (1993) y Arnoux (2008), se denomina ortografía casera o chilena.

Otro aspecto del discurso lingüístico que es posible ver en la obra de Suárez, y que va más allá del tratamiento propiamente ortográfico que se realiza del español de Chile, son los sesgos y normas de tipo gramatical, estilístico y valorativo que podemos encontrar en el nivel paratextual del P2.

Por un lado, las constantes citas y referencias en el texto, corresponden a uno de estos recursos paratextuales en los que podemos reconocer ciertos

12 Proponer el criterio de uso constante como solución a los escollos que no cubre el criterio de pronunciación, es algo que Suárez explicita detalladamente solo en el P1, pues en el P2, el autor solo se limita a destacar la importancia del criterio de pronunciación y a mencionar que para solucionar los demás problemas que surgen al escribir se dictarán algunas reglas que prescindirán del criterio etimolójico. Por lo tanto, el autor nos demuestra que en su reedición del Prontuario de ortografía, de los tres criterios ortográficos existentes, sigue rigiéndose por los dos que planteó en un inicio, es decir, el de pronunciación y el de uso constante. 
modelos o ideas acerca de cómo escribir correctamente, ya que una de sus funciones dentro del manual era aludir a importantes intelectuales del contexto chileno y español.

De ahí que en el P2 hallemos a autores como Andrés Bello, Eusebio Lillo, Guillermo Blest Gana y Miguel Luis Amunátegui, entre otros, representando al grupo de intelectuales chilenos; y a figuras como Vicente Salvá, Félix M ${ }^{\mathrm{a}}$ Samaniego, Tomas José González Carvajal, Alberto Lista, etc., representando al bando español.

Todos estos autores fueron considerados como autoridades y modelos de la buena escritura en Chile, por lo que su selección e introducción en el P2 no fue un asunto que Suárez dejó al azar. Cada uno de estos intelectuales, tanto chilenos como españoles, resultaron ser grandes exponentes de las ideas ilustradas que en ese momento se estaban intentando inculcar en nuestro país.

Los nombres españoles encontrados correspondían a conocidos escritores pertenecientes al grupo de literatos afrancesados de la península, quienes muchas veces por circunstancias políticas emigraron a alguna zona francesa y tuvieron contacto directo con los ideales ilustrados de ese lugar. Asimismo ocurre con las figuras chilenas que expone Suárez, ya que todas ellas correspondían a intelectuales liberales que, además de practicar y difundir los ideales ilustrados provenientes de Europa (Conejeros 1999), conformaron la nueva elite criolla que se encargó de consolidar los procesos de construcción de la nación, tarea que desempeñaron mediante la creación y difusión de una literatura propia basada en ideas y motivos ilustrados franceses, y a partir de una reforma educativa fundamentada en estos mismos preceptos.

Ante esta situación, cabe destacar que de todos los autores expuestos en el P2, Andrés Bello y Vicente Salvá fueron las autoridades más citadas, lo que seguramente se debe a la magnitud de sus obras, y en el caso de Bello, a la importante participación que tuvo en el ámbito político, social y sobre todo educativo de nuestro país.

La influencia y autoridad que representaban todos estos intelectuales llega a tal punto que incluso nos parece percatarnos que Suárez en algunas oportunidades, más allá de referir a los aportes propios de Salvá, se habría concentrado en extraer las citas que el español ya había seleccionado desde otras obras.

En el CUADRO ${ }^{\circ} 1$ observamos cómo Suárez cita un fragmento de Alberto Lista para dar un ejemplo del uso correcto del signo coma, el que ya había citado Salvá en su Gramática de la lengua Castellana en 1839 para explicar el mismo signo de puntuación.

Dicha situación nos hace pensar que, tal vez, Suárez no siempre citó directamente desde las fuentes literarias que señala sino que también, copió 
fragmentos que ya habían citado otros renombrados autores, así como podría ser el caso de la cita recién mencionada ${ }^{13}$.

\begin{tabular}{|c|c|}
\hline $\begin{array}{c}\text { Prontuario de Ortografía } \\
\text { Práctica }(1865)\end{array}$ & $\begin{array}{c}\text { Gramática de la Lengua } \\
\text { Castellana (1839) }\end{array}$ \\
\hline $\begin{array}{l}\text { De la coma (,) } \\
\text { Regla novena }\end{array}$ & DE LA PUNTÜACION \\
\hline $\begin{array}{l}\text { En ocasiones se hace necesaria la } \\
\text { coma para evitar ambigüedades; } \\
\text { lo que ocurre con frecuencia al } \\
\text { que escribe en verso }[\ldots] \text { : }\end{array}$ & $\begin{array}{c}{[\ldots] \text { Donde ocurren inversiones, es }} \\
\text { preciso á vezes colocar una coma en } \\
\text { medio de la oracion, á pesar de que } \\
\text { parece repugnarlo la sintáxis }[\ldots]\end{array}$ \\
\hline ¡Ai, qué demencia! ¿Es posible & Ai, qué demencia! ¿es posible \\
\hline Que por las iras crueles & Que por las iras crueles \\
\hline De un amigo, el halago & De un amigo, el halago \\
\hline De una amante esposa trueques? & De una dulce amante trueques? \\
\hline
\end{tabular}

Cuadro $\mathrm{n}^{\circ} 1$. Fragmentos del artículo y de los ejemplos de la Regla Novena para el signo de coma, extraídos del P2 y de la "Gramática de la Lengua Castellana" de Vicente Salvá (1839)

Por otro lado, las notas a pie de página también nos permitieron identificar ciertas ideas lingüísticas, debido a que este tipo de recurso, al ampliar el contenido que se encuentra en el cuerpo del texto, cumple la función general de comentar, desarrollar e incluso evaluar algunos aspectos del lenguaje.

\section{NOTA N ${ }^{\circ} 1$}

“(1) Los co-pretéritos i pos-pretéritos en ia no llevan pintado el acento: tenia, tenian; temeria, temerias, temerian” (Suárez 1865: 34).

13 Es importante destacar que en el proceso de comparación entre el fragmentado de Suárez y Salvá, nos percatamos de que las citas difieren en una de sus frases. En la estrofa citada por Suárez en el P2 aparece el sintagma "amante esposa" y en el fragmento extraído de Salvá, que por lo demás es igual al de Alberto Lista, aparece el sintagma "dulce amante". A nuestro parecer, esta pequeña modificación en Suárez, con respecto al verso original, nos da cuenta de un proceso de adaptación que afecta a ciertos fragmentos citados en los Prontuarios, de acuerdo con las ideas morales que Suárez expone para el aprendizaje de su público infantil. 


\section{NOTA N²}

“(1) Debo citar aquí dos escepciones introducidas por el uso: HACEN calores, HACEN fríos” (Suárez 1865: 83).

De esta manera, el autor se ve en la necesidad de remitirse en sus notas a los modelos, autoridades o normas lingüísticas vigentes en la época, ya sean estas, normas de carácter académico o simplemente normas de uso constante. Todo con el objetivo de dar a conocer cuáles eran los usos de la lengua que se consideraban correctos por la comunidad chilena.

\subsubsection{El discurso lingüístico en los anexos: el Apéndice y las Advertencias}

Por su parte, los anexos añadidos en la reedición del manual de Suárez, vale decir, el Apéndice sobre nociones de gramática práctica y las Advertencias sobre el uso de la lengua castellana, dirijidas a los padres de familia, profesores de los colejios y maestros de escuela, resultan ser los recursos paratextuales donde se identifica con mayor claridad el discurso lingüístico contenido en el manual de Suárez.

En el apéndice se presentan 68 puntos que exponen aspectos gramaticales como: la conjugación y derivación de algunas palabras, la formación de ciertos sintagmas, y la corrección de algunos usos que eran considerados incorrectos para la época. Cada uno de estos puntos se encuentran repartidos en cuatro subapartados que exponen la información gramatical mediante lo que denominamos: modalidad pregunta-respuesta.

"1. ¿Cómo hacen los plurales de los nombres sustantivos alférez, lord, club, complot, álbum, frac? Hacen alféres, lores, clubs, complots, álbums, fraques" (Suárez 1865: 67).

Como se observa en el ejemplo recién expuesto, la mayoría de las veces la información gramatical se presenta según esta modalidad, donde a partir de una fórmula interrogativa sencilla y su correspondiente respuesta, se indica cuáles son los usos de la lengua que se consideran correctos.

En otras ocasiones, dicha modalidad interrogativa se plantea de forma diferente con el objeto de presentar, de modo más explícito, las faltas lingüísticas que se cometen comúnmente. Para ello se comienza la frase o pregunta evidenciando cuáles son los vocablos erróneos y en seguida se cuestiona si tales usos están o no "bien dichos" o si "deben decirse" o "no deben decirse" de tal o cual forma, como muestran los siguientes ejemplos: 
“24. ¿Estará bien dicho, vACÉA ese tintero, COPÉA esa cuenta, le AGRACÉA aquel vestido? Mui mal dicho: es necesario decir vacía ese tintero, cóPIA esa cuenta, le AGRÁCIA aquel vestido [...]" (Suárez 1865: 73).

"25. ¿Cómo deberá decirse yo tueso o yo toso? Debe decirse yo toso [...]" (Suárez 1865: 73).

De esta manera, la modalidad de preguntas y respuestas desde la que se articula el discurso lingüístico en el apéndice nos revela las valoraciones positivas y negativas que se tienen hacia ciertos usos de la lengua. Estas evaluaciones pueden hallarse mediante la identificación de marcas normativo-prohibitivas que tienen relación con pares conceptuales como: bien/mal, correcto/incorrecto, agradable/desagradable, etc., y con expresiones deónticas como: "debe o no debe" decirse, evitarse, etc. Tal como nos muestra el destacado en negrita del siguiente ejemplo:

“37. [...] Hablan, pues, pésimamente los que, concordándolo con la segunda singular, dicen: vos eres, vos estás [...] Igualmente se habla mal diciendo: trajieron, trajiese [...] Otro vicio mui comun que se debe evitar, es decir quedrá doldrá, en vez de querrá, dolerá [...] Desagradable es también oír: aunque HAIGA mucha jente, etc. debiendo decir aunque HAYA, etc. [...] (Suárez 1865: 76-77).

En el caso del apartado de advertencias sobre el uso de la lengua castellana ocurre algo distinto. A simple vista podemos apreciar que el contenido de este anexo se trata realmente de algunos fragmentos rescatados por Suárez desde los trabajos de Bello. Tal situación se hace explícita, al ver que el título de las advertencias del P2 es idéntico al título que presenta Bello en las advertencias de su obra gramatical, hecho que además se confirma en el subtítulo que encontramos en este mismo anexo, donde se menciona concretamente que la información presentada por Suárez ha sido "[e]stractada por el autor del Prontuario, de los Opúsculos Gramaticales del señor Bello" (Suárez 1965: 91).

El hecho de que Suárez haya incluido estos fragmentos en la reedición de su Prontuario, creemos que no solo se debe a que Andrés Bello era el exponente más importante de la época y el rector de la Universidad de Chile, sino que también por las ideas pedagógicas y lingüísticas que exponía el trabajo, aquellas que eran concordantes con la formación y el pensamiento de Suárez.

De esta manera, creemos que la correspondencia entre el pensamiento de Bello y Suárez se encontraría en los siguientes aspectos detectados en las advertencias: 
i. Se dirigen a un público mixto (infantil y adulto), compuesto por niños, padres, maestros de escuela y profesores de colegio.

ii. No solo entregan información gramatical, sino que también exponen los errores más comunes que se cometen en términos de acento ortográfico y pronunciación, como indican los siguientes fragmentos:

"2. Nada es mas comun, aun entre las personas de buena educacion, que alterar el acento de la segunda persona del imperativo de casi todos los verbos, diciendo: verbi-gracia: mirá, andá, levantáte, sentáte, sosegáte; palabras todas que no existen i deben evitarse [...] (Bello cit. en Suárez 1865: 91).

3. Es necesario hacer sentir la $d$ de las palabras que la tienen, como usted, virtud, vanidad' (Bello cit. en Suárez 1865: 91).

iii. Y también, porque estratifican y estigmatizan el uso de ciertos vocablos, expresando de modo claro que los usos correctos pertenecen a los sectores educados de la población y los usos incorrectos a personas vulgares, ignorantes, de provincia o del bajo pueblo, situación que se expresa mediante frases como las destacadas a continuación:

"13. En Chile, la ínfima plebe, muda siempre en is la terminación eis de los verbos, diciendo vís, comis, juntís, en lugar de veis [...]" (Bello cit. en Suárez 1865: 92).

"18. Suele decirse comunmente fui a lo de Pedro, estábamos en lo de Juan. Se debe evitar estos provincialismos i lo de, porque sobre ser desautorizado, es equivoco i mal sonante" (Bello cit. en Suárez 1865: 93).

Cada uno de estos puntos nos confirma dos aspectos. Uno primero, que hace alusión al modelo de lengua correcta del Chile postindependentista, puesto que todos los intelectuales de la época, incluyendo Suárez, concluían que la norma culta o educada era la variedad de español legítima que debía difundirse; y uno segundo, que refiere al sector de la población hacia el que iba dirigida la educación, ya que tanto Suárez como Bello y Sarmiento creían necesario implantar una educación integral dirigida hacia todos los sectores de la población chilena ${ }^{14}$.

En resumen, en ambos anexos el discurso lingüístico está fuertemente presente, debido a que el rechazo a ciertos usos y su prohibición aparecen de modo más explícito. El apéndice y las advertencias finalmente cumplen

14 Este último punto acerca del público a quien iba dirigida la obra ortográfica de Suárez lo desarrollaremos más adelante en el apartado $\mathrm{N}^{\circ} 6$. IDEAS PEDAGÓGICAS DE SARMIENTO. 
con crear una consciencia lingüística en el lector, ya que al resolver los problemas más relevantes acerca de ciertos usos conflictivos de la lengua, se están presentando e instaurando las ideas y normas lingüísticas vigentes en la época.

\title{
5.2. DisCURSO POLÍTICO-SOCIAL
}

Como mencionamos más arriba, junto al discurso lingüístico opera simultáneamente lo que denominamos discurso político-social, aquel que contribuyó con el proceso de consolidación del Estado y la Nación mediante la exposición de las ideologías políticas, sociales y culturales del contexto chileno del siglo XIX. Esto con el objetivo de reflejar el modo de ser de la sociedad e inculcar ciertos valores y creencias en el público infantil a quien iba dirigido el plan de estudios del Prontuario de ortografía.

Según lo revisado en el P2, el discurso político-social se presenta de un modo más implícito a como se expone el discurso lingüístico. Esto se logra a partir de la integración de ejemplos, ejercicios para la pizarra, citas y notas a pie de página, todos ellos recursos paratextuales mediante los que el autor hace constante alusión a temas patrióticos, religiosos y morales (o relativos a la buena conducta) que logran reflejar el carácter y las ideologías de la sociedad chilena de ese entonces.

Estas temáticas adoptadas y expuestas por Suárez en el P2 corresponden a otra de las prácticas puestas en marcha por orden de la Ley Orgánica de Instrucción Pública de 1860, ya que en el artículo $3^{\circ}$ de dicho documento se señala cuáles son los contenidos obligatorios (Curriculum escolar) que deben abordarse en la educación chilena:

\begin{abstract}
"Habrá dos clases de escuelas, elementales i superiores. En las primeras se enseñará, por lo ménos, lectura i escritura del idioma patrio, doctrina i moral cristiana, elementos de aritmética práctica i el sistema legal de pesos i medidas. En las superiores, a mas de los ramos designados, se dará mayor ensanche a la instruccion relijiosa, i se enseñará gramática castellana, aritmética, dibujo lineal, jeografía, el compendio de la historia de Chile i de la constitucion política del Estado, i, si las circunstancias lo permiten, los demas ramos señalados para las escuelas normales" (Ballesteros 1872: 269).
\end{abstract}

La gran cantidad de intervenciones que Suárez realiza en el P2 a través de los recursos paratextuales antes mencionados, nos permitió observar cómo y en qué medida estas temáticas patrióticas, religiosas y morales conformaron 
el discurso político-social con el que se adoctrinaba a los niños de la escuela primaria.

\begin{tabular}{|l|l|}
\hline $\begin{array}{c}\text { Temática de } \\
\text { Adoctrinamiento }\end{array}$ & \multicolumn{1}{c|}{ Tipo de información que entregan } \\
\hline Patriótica & $\begin{array}{l}\text { Se alude a Chile en cuanto a: } \\
\text { 1) su orden político y social: formas de organización de la } \\
\text { sociedad y el Estado. } \\
\text { 2) su orden fisico: características sobre la geografía y el } \\
\text { territorio. } \\
\text { 3) su orden histórico: mención a hitos chilenos. }\end{array}$ \\
\hline Religiosa & $\begin{array}{l}\text { Establece el "deber ser católico" mediante el uso de } \\
\text { proverbios, mandamientos adaptados, breves relatos } \\
\text { biográficos de figuras santificadas, reflexiones religiosas de } \\
\text { algunos intelectuales, etc. }\end{array}$ \\
\hline Moral & $\begin{array}{l}\text { Da cuenta de dos aspectos de la buena conducta: } \\
\text { 1) la moral y el buen comportamiento en sociedad. } \\
\text { 2) la buena conducta del alumno con respecto a sus deberes } \\
\text { como estudiante. }\end{array}$ \\
\hline
\end{tabular}

Cuadro ${ }^{\circ} 2$. Temáticas de adoctrinamiento contenidas en el discurso normativo de los Prontuarios de ortografía de Suárez

Según podemos ver en el Cuadro $\mathrm{N}^{\circ} 2$, la temática patriótica solía referirse a tres puntos principales que destacaban las características y bondades de Chile. Estos son: el modo en el que se organizaba la sociedad, ej., una lei abolió en Chile los mayorazgos; el aspecto físico y geográfico, ej. Todo presenta en Chile un porvenir de riquezas, los muchos i caudalosos ríos que lo cruzan, las llanuras de la parte central, la fertilidad de sus campos, los escelentes puertos que se estienden a lo largo de la costa, etc. [...]; y también, algunos hechos históricos que estuvieron asociados al proceso de independencia chileno, ej., Destrozado el ejército realista en la memorable jornada de Chacabuco (1817), i elejido Supremo Director el Jeneral don Bernardo O'Higgins (16 de febrero de id), Chile se declaró Nacion independiente ante los demas pueblos del mundo [...].

A partir de este tipo de menciones, el autor pretendía concientizar a su público infantil con la idea de que Chile era un país soberano, situación que además de generar un sentimiento de unidad e identidad en los jóvenes buscaba acelerar la consolidación de los procesos políticos e ideológicos iniciados en la independencia. 
Cabe agregar que el patriotismo presente en la obra de Suárez también se puede identificar cuando hallamos oraciones que resaltan el carácter heroico del trabajo de los generales, coroneles y soldados, quienes en ese entonces eran considerados figuras importantes por haber protagonizado episodios de guerra y cambios, antes y durante la independencia de Chile. Debido a esto, tanto en la reedición como en la primera versión del manual de ortografía de Suárez, es común encontrar fragmentos donde se ensalza la imagen de mártir de algunos miembros de la armada chilena, así como ilustra la siguiente oración: Se ve por lo dicho que entre Freire i Benavides (perdóneseme que los compare) no habia nada mas de comun que el valor (Suárez 1865: 59).

De igual modo, en el P2 encontramos una cita que corresponde a un fragmento del himno nacional chileno, cuya aparición, a nuestro parecer, resultó ser el ejemplo más representativo de esta temática patriótica, y donde además se aprovecha de hacer visible el nombre de Eusebio Lillo, poeta y político que formó parte de la lista de intelectuales que difundieron los ideales ilustrados en Chile.

"Puro Chile, es tu cielo azulado;

Puras brisas te cruzan tambien,

I tu campo de flores bordado

Es la copia feliz del Eden.- (LILLo)"

Por su parte, el fuerte catolicismo que practicaba la sociedad chilena del siglo XIX, representa otra de las esferas que se plasma en la obra ortográfica de Suárez. A diferencia de la temática patriótica, en el P2 el catolicismo solamente se expresó de modo implícito en tres oportunidades, cuando se presentaron breves relatos biográficos de figuras santificadas, ej., Vicente de Paul nació de padres pobres i se hizo célebre por sus virtudes; en oraciones o versos que contaban las hazañas de Jesucristo y engrandecían la figura de Dios, ej., Jesucristo murió en la cruz por liberarnos de la muerte eterna; y cuando se hallaron alusiones o definiciones de conceptos cristianos, ej., Los ánjeles son espiritus celestiales.

Por el contrario, el resto de las alusiones de carácter religioso se realizó mediante proverbios y referencias a algunos mandamientos cristianos, lo que muchas veces demostró un carácter más directivo en la enunciación del mensaje.

Así, en frases como: Siempre tierno i cariñoso ama a tu Dios bondadoso, y No abandonemos la religión católica, que nos enseña a creer en Dios, a esperar en él i a amarle sobre todas las cosas, además de enseñarse cómo 
ser cristiano, se expresaba la importancia y el deber de ser católico, de alabar a Dios y de obrar según lo ordenaban los mandamientos y la fe de la Iglesia.

Finalmente, y de la mano del pensamiento católico, en el P2 nos es posible ver cómo se insertaron en todo momento ideas y pensamientos que tienen relación con la moral y las buenas costumbres. Tales frases u oraciones aleccionadoras dirigidas a los niños adoctrinaban en dos aspectos: uno relativo a la moral y el buen comportamiento en sociedad, ej., $L a$ perseverancia triunfa al fin de las resistencia, No debemos despreciar a nadie, ni codiciar los bienes ajenos; $\mathrm{y}$ otro relativo a los deberes estudiantiles y la buena conducta del niño en la sala de clases, ej., El alumno debe prestar atencion a las esplicaciones de su preceptor, El buen alumno es incapaz de faltar a sus deberes.

De igual forma, ambos aspectos morales se encargaron de inculcar en los alumnos valores como el esfuerzo, la responsabilidad, el respeto, la obediencia y la sumisión, cualidades que en la época se consideraron necesarias para asumir la vida en sociedad.

Además, como bien plantea Serrano et al. (2012), junto a la temática moralizadora que se encontraba recurrentemente en libros y textos de enseñanza, también se hallaron textos que poseían un carácter instructivo, cuyo objetivo era entregar nuevos conocimientos. Esta intención también está presente en el P2, ya que identificamos algunos recursos paratextuales que dan cuenta de nociones básicas acerca del medio natural y cultural que les permiten a los alumnos relacionarse y comprender el mundo en el que viven.

De tal modo, en citas, ejercicios para la pizarra y ejemplos, encontramos frases que informaban sobre historia europea, ej., Alejandro, hijo de Filipo $i$ rei de Macedonia, venció a Darío, rei de Persia, en los llanos de Arbela [...]; y americana, ej., El antepenúltimo de estos monarcas, Huaina Cápac, muerto hacia pocos años, habia sido un gran conquistador, que habia agregado por la fuerza de las armas el reino de Quito a sus dominios hereditarios. Así como también, sobre otros conocimientos básicos del mundo que contribuían a la instrucción de los alumnos de escuela primaria, ej., La época del año en que el dia crece desde la duracion media de doce horas hasta la duracion máxima que corresponde a la latitud de cada lugar, se llama primavera.

En suma, las temáticas patriótica, religiosa y moral que se hallaron tanto en la $1^{\mathrm{a}}$ como en la $2^{\mathrm{a}}$ edición del Prontuario de Suárez permitieron que los alumnos de escuela primaria recibieran un contenido implícito que, si bien no representaba para ellos el objetivo principal de aprendizaje en su paso por la escuela (contenidos ortográfico y gramatical), correspondía, de todas formas, a parte del objetivo del plan educativo de esa época. 


\section{IDEAS Y ESTRATEGIAS PEDAGÓGICAS}

Como hemos podido corroborar, el discurso normativo que Suárez expone en la reedición de su Prontuario de ortografía corresponde a un doble discurso donde se relacionan aspectos acerca del lenguaje (discurso lingüístico) y del contexto de producción del manual (discurso político-social).

Pese al trato separado que hasta el momento le hemos prestado a cada uno de ellos, es importante mencionar que estos discursos no funcionan de tal forma, sino que al contrario, ya que dependen el uno del otro para conformar el discurso normativo que fue entregado por el trabajo ortográfico de Suárez a los alumnos de las escuelas primarias.

Ahora bien, si observamos más detenidamente nos percataremos que esto se debe a que Suárez logró articular la información presentada por ambos discursos no solo en el texto (en cuanto a redacción y coherencia del contenido escolar), sino que también mediante algunas ideas y prácticas pedagógicas que estando plasmadas en su manual facilitaron la tarea de enseñanza de los contenidos primarios.

Así, en la reedición del manual ortográfico hallamos diversas indicaciones y consejos que iban dirigidos hacia los maestros, pues eran estas las estrategias mediante las que Suárez pretendía instruir y guiar a los docentes en su labor educativa.

Un ejemplo de esto se halla en la presentación del P2 cuando Suárez indica como una de sus novedades la utilización de ejercicios para la pizarra, elemento que habría sido integrado en la educación chilena por haber obtenido buenos resultados en sistemas de educación de otras partes del mundo.

"Para la enseñanza de este ramo recomiendo a los señores profesores mui especialmente el uso de la gran pizarra, este poderoso auxiliar que el sistema simultáneo ha introducido en las escuelas, i que no debe faltar en ninguna de ellas. El maestro aleman se vale de la pizarra hasta para la enseñanza de los principios de la lectura, i el institutor yankee no podria sin su auxilio enseñar con perfeccion la jeografía” (Suárez 1865: 6).

Más adelante, el autor menciona que la incorporación de este tipo de recurso pretende afianzar en la memoria de los alumnos aquellos conocimientos que fueron adquiridos en la sala de clases y que temen olvidarse. Para que esto no ocurra, Suárez señala que el profesor debe escribir en la pizarra ojalá la 
totalidad de los ejercicios que trae el Prontuario, ya que entre más pudieran copiar los alumnos, más útil y práctico resultaría el método ${ }^{15}$.

De igual forma, se presenta en el P2 una breve sección titulada Advertencias dirigidas a los profesores primarios. Esta breve sección actúa como un discurso de cierre dentro del Prontuario, pues además de encontrarse en la última página de lo que sería formalmente el Prontuario de Ortografía Práctica, funciona como un instructivo sobre cómo deben ser abordados los contenidos del manual por parte de los maestros de escuela.

Para lograr esta idea de instructivo se ordenó la sección de acuerdo con dos puntos. En el primero, Suárez plantea nuevamente que la enseñanza de los alumnos debe realizarse mediante el método de los ejercicios para la pizarra, dado que la práctica de la escritura permitía afianzar los conocimientos en la memoria de los alumnos. Y en el segundo punto, el autor se encarga de indicar cómo y en qué orden debían abordarse los contenidos de letras, acentuación y puntuación que conformaban los tres apartados del manual de ortografía ${ }^{16}$.

A partir de estas dos estrategias de enseñanza se puede apreciar cómo Suárez concreta en su trabajo una labor de guía dirigida hacia el preceptorado en general. Creemos que esta idea debe ser el resultado de la formación de Suárez en la Escuela Normal de Preceptores y de los pensamientos pedagógicos que adoptó de su maestro Sarmiento, ya que este último consideraba de vital importancia el rol del preceptor en la educación, pues, como bien menciona Serrano et al. (2012), no solo bastaba con que los textos o manuales escolares presentaran de manera idónea los contenidos correspondientes al currículum educativo, sino que también se necesitaba a profesores que fueran capaces de entregarlos a los alumnos.

Por su parte, las Advertencias sobre el uso de la lengua castellana [...] que fueron extractadas de la obra de Bello también dan cuenta de otra de las ideas pedagógicas de Suárez. Los contenidos ortográficos y gramaticales que aparecen en este anexo (como ya vimos en el apartado 5.1.1.) iban dirigidos hacia un público mixto que además de aleccionar a un público infantil

15 Si bien los ejercicios para la pizarra se introducen en la reedición, la idea en sí de que los ejemplos o ejercicios mejoran el aprendizaje de los niños (por la práctica de las reglas) ya se encontraba planteada en el P1 mediante una nota a pie de página que aconsejaba a los preceptores dictar ejemplos en la clase con el fin de afianzar los conocimientos de ciertas reglas.

16 Este último punto se resume en palabras del mismo Suárez, quien cree que "es necesario desde temprano familiarizar a los niños con la buena ortografía, sobre todo en la parte relativa al uso de las letras i los acentos, que se les puede enseñar prácticamente i sin mayor trabajo" (Suárez 1865: 65). 
incluyen a un público adulto instruido, como es el caso de los maestros, y a un público adulto no instruido, como los padres de familia.

$\mathrm{Al}$ dirigirse a otras entidades de la sociedad chilena en la instrucción de la lengua, Suárez estaba realizando una extensión de la educación en Chile, lo que se interpreta como una estrategia pedagógica que operaba en pos de un proyecto mayor, como era el de instruir para civilizar a la población chilena en general.

Este punto además nos indica cómo el Prontuario de Ortográfica Práctica de Suárez fue parte del cambio de pensamiento que se gestó con respecto al tema educativo en la década de 1860, momento en el que se promulga la Ley Orgánica de Instrucción Pública. El hecho de que Suárez abogara por una educación extensiva que alcanzara todos los sectores de la población chilena, incluyendo a los padres, demuestra cómo el preceptor primario mediante su obra ortográfica estaba siendo participe de un proceso educativo que intentó dar un vuelco a la situación de marginalidad de la educación de los años 40 y 50, donde la familia chilena fue evaluada como un "ente desorganizado e imposibilitado de educar a sus infantes" (Serrano et al. 2012: 191), por preferir la vida laboral para sus hijos antes que su educación.

En consecuencia, al añadir las advertencias de Bello en el P2, Suárez además de incentivar la adquisición de ciertas conductas y hábitos lingüísticos en los niños, instaba también a la instrucción de los padres y a la actualización del saber de los maestros. Hecho con el que al mismo tiempo esperaba modificar la concepción que tenían las familias trabajadoras sobre la educación.

Todo esto explica por qué las ideas y estrategias pedagógicas que Suárez desplegó en su manual de ortografía se hallaron expresadas por medio de indicaciones o consejos hacia los maestros. La finalidad de estos mecanismos pedagógicos era articular de modo adecuado la entrega del discurso normativo del Prontuario para conseguir la simplificación de la enseñanza, lo que consecuentemente haría más extensiva y accesible la educación en la población chilena.

Finalmente, esto nos demuestra que el interés y el compromiso de Suárez con la labor educativa se debían a que él creía acérrimamente, al igual que Sarmiento, que la educación del pueblo era la clave para la civilización de la sociedad y la felicidad de las naciones (Suárez 1865). 


\section{CONCLUSIONES Y COMENTARIOS FINALES}

La presente investigación nos ha permitido observar que el Prontuario de Ortografia Práctica (1865) de José Bernardo Suárez fue una herramienta estandarizadora de la lengua que se sirvió de un nivel textual y otro paratextual para organizar su contenido.

El hecho de que la información ortográfica, o cuerpo del texto del Prontuario, se halle interactuando constantemente con diversos recursos paratextuales, tales como: ejemplos, ejercicios para la pizarra, citas y notas a pie de página, entre otros recursos, nos permitió identificar cómo Suárez construyó en la reedición de su trabajo ortográfico lo que Arnoux (2008) denominó discurso normativo.

Según nuestro análisis, el discurso normativo del P2 se trata de un doble discurso que se constituyó a partir de un discurso lingüístico y un discurso político-social, cuya relación permitió que se introdujeran aspectos sobre el lenguaje y sobre el contexto chileno de mediados del siglo XIX en un instrumento destinado a la enseñanza.

El discurso lingüístico instruyó sobre el uso correcto de la lengua en cuanto a su aspecto ortográfico, gramatical y estilístico, por medio de la exposición de las propuestas lingüísticas vigentes en la época y de acuerdo con referencias a ciertas autoridades que se concebían como modelos de escritura correcta. Así como también dio cuenta de las valoraciones positivas y negativas que los mismos hablantes ya utilizaban para calificar los usos correctos e incorrectos de la lengua. Todo esto con el objetivo de eliminar los constantes vicios del lenguaje y alcanzar la unificación de las prácticas lingüísticas de la sociedad chilena.

En cambio, el discurso político-social moldeó el pensamiento y la conducta de los alumnos de escuela primaria, mediante la exposición de temáticas patrióticas, religiosas y morales que reflejaban las ideologías políticas, sociales y culturales del contexto chileno. Esto con la finalidad de inculcar ciertos valores y creencias que, a medida que modificaban el comportamiento de los niños, contribuían con el proceso de consolidación del Estado y la nación chilenos en el siglo XIX.

La presencia de los aspectos lingüísticos y político-sociales, y la relación de dependencia que entre estos se genera para la conformación del discurso normativo ofrecido en el Prontuario de Suárez, se debe a que el autor desplegó ciertas ideas y estrategias pedagógicas que le permitieron entregar toda la información contenida en su manual de un modo dinámico y adecuado al lector infantil. 
Las prácticas pedagógicas adoptadas por Suárez quedaron en evidencia cada vez que nos encontramos con indicaciones, instrucciones o consejos que iban dirigidos hacia los maestros con el fin de guiarlos en su labor educativa. A partir de estas estrategias, Suárez estableció el modo en que debían abordarse los contenidos de los Prontuarios para conseguir la simplificación de la enseñanza y hacer más accesible la educación a la población chilena.

En este sentido, y respondiendo a los objetivos planteados al comienzo de esta investigación, podemos decir que el pensamiento pedagógico y las ideas lingüísticas propuestas por Suárez en el Prontuario de Ortografía Práctica se unen en pos de un proyecto mayor como es el de la consolidación del Estado y la nación chilenos.

Las indicaciones dirigidas hacia los maestros, las recomendaciones sobre la utilización de la pizarra, la exposición de las propuestas ortográficas de la época, las reiteradas veces que Bello es situado como una autoridad lingüística y los constantes pasajes de los manuales que expresan valoraciones positivas y negativas sobre el uso correcto e incorrecto de la lengua representan solo algunas ideas pedagógicas y lingüísticas, que nos permiten observar cómo el P2, además de poner en práctica el pensamiento pedagógico de Suárez, puso en marcha la enseñanza de un universo ideológico que va más allá del universo del lenguaje.

En síntesis, podemos decir que los resultados arrojados por esta investigación se encuentran en completa consonancia con los resultados obtenidos por otros estudios glotopolíticos que se han dedicado al análisis de instrumentos estandarizadores, como diccionarios y gramáticas.

El presente análisis nos reveló cómo Suárez mediante prácticas pedagógicas permitió la operatividad del lenguaje (Arnoux y Del Valle 2010) en un contexto social, político y cultural determinado, hecho que consecuentemente nos informó acerca de cómo se efectuó el proceso de unificación lingüística y en qué medida se aportó al proceso de consolidación del Estado y la nación chilenos mediante una herramienta estandarizadora de lenguaje.

De este modo, creemos que es crucial que se siga desarrollando la línea investigativa de la etnortografía, ya que este tipo de estudios demostró ser tierra fértil en el ámbito de la disciplina glotopolítica, por el hecho de revelar las diversas ideologías políticas y socioculturales que se presentan en contextos donde las ideas lingüísticas se encuentran aún en debate, en proceso de reformulación, o bien, en camino a ser estandarizadas. Así como fue el caso de los tiempos de reforma o revolución ortográfica (Sebba 2007) en que se creó el Prontuario de ortografía de José Bernardo Suárez. 


\section{REFERENCIAS BIBLIOGRÁFICAS}

Arnoux, Elvira Narvaja de. 2006. Marcar la nación en la lengua: la reforma ortográfica chilena (1843-1844). Ámbitos 16: 41-54.

2008. Los discursos sobre la nación y el lenguaje en la formación del Estado (Chile, 1842-1862). Estudio glotopolítico. Buenos Aires: Santiago Arcos.

Arnoux, Elvira Narvaja de, y José del Valle. 2010. Las representaciones ideológicas del lenguaje. Discurso glotopolítico y panhispanismo. Spanish in Context 7(1): 1-24.

Ballesteros, Manuel E. 1872. Compilación de Leyes y Decretos vijentes en materia de instruccion publica. Santiago: Imprenta de El Independiente.

Bello, AndRÉs. 1884. Opúsculos gramaticales de Bello. Obras completas de Don Andrés Bello. Edición hecha bajo la dirección del Consejo de instrucción pública en cumplimiento de la lei de 5 de Septiembre de 1872. Vol.5. Santiago: Impreso por Pedro G. Ramírez [En línea]. Disponible en: http://www.memoriachilena.cl/archivos2/pdfs/MC0064755.pdf [Consulta 13/12/2015].

Bravo, Eva. 2010. La construcción lingüística de la identidad americana. Boletín de Filología $X L V(1): 75-101$ [En línea]. Disponible en: http://www.boletinfilologia.uchile.cl/index. $\mathrm{php} / \mathrm{BDF} /$ article/viewFile/1323/1214 [Consulta 06/11/2015].

Calero Vaquera, María Luisa. 2010. Ideología y discurso lingüístico: la Etnografía como subdisciplina de la glotopolítica. Boletín de Filología XLV (2): 31-48 [En línea]. Disponible en: http://www.boletinfilologia.uchile.cl/index.php/BDF/article/viewFile/17994/18788 [Consulta 10/10/2015].

Conejeros, Juan Pablo. 1999. La influencia cultural francesa en la educación chilena, 1840-1880. Santiago: Dirección de Investigación y Extensión de la Universidad Católica Cardenal Raúl Silva Henríquez.

Contreras, Lidia. 1993. Historia de las ideas ortográficas en Chile. Santiago: Centro de Investigaciones Diego Barros Arana.

Del Valle, José. 2007. Glotopolítica, ideología y discurso: categorías para el estudio del estatus simbólico del español. La lengua ¿patria común? Ideas e ideologías del español. Francfort y Madrid: Vervuert e Iberoamericana.

2014. Lo político del lenguaje y los límites de la política lingüística panhispánica. Boletín de Filología XLIX (2): 87-112 [En línea]. Disponible en: http://www. boletinfilologia.uchile.cl/index.php/BDF/article/viewFile/35824/37470 [Consulta 20/09/2015].

Haugen, Einar. 1966. Dialect, language, nation. American Anthropologist 68(4): 922-935.

Kroskrity, Paul. V. 2010. Language ideologies -Evolving perspectives. En J. Jaspers, J. O. Östman \& J. Verschueren (eds.). Society and Language Use, pp. 192-211. Amsterdam/ Philadelphia: John Benjamins.

LabARCA, Amanda. 1939. Historia de la enseñanza en Chile. Santiago: Imprenta Universitaria.

Lara, Luis Fernando. 1976. El Concepto de Norma Lingüistica. México: El Colegio de México.

Matus, Alfredo, Soledad Dargham y José Luis Samaniego. 1992. Notas para una historia del español en Chile. Historia y presente del español de América. Coord. César Hernández. Valladolid: Junta de Castilla y León / PABECAL. 543-564.

Metzeltin, Miguel. 2011. La construcción discursiva de la República de Chile. Boletín de Filología XLVI(1): 239-253 [En línea]. Disponible en: http://www.boletinfilologia.uchile. cl/index.php/BDF/article/viewFile/18041/18823 [Consulta 16/05/2015].

Salas Neumann, Emma. 2010. El maestro del Héroe de Iquique José Bernardo Suárez. Memorias del escritorio segundo. Santiago: $2^{\mathrm{a}}$ ed. [s.n.]. 
Sarmiento, Domingo F. 1988 [1843]. Memoria (sobre ortografía americana) leída a la Facultad de Humanidades. En Alamiro Avila Martel, Sarmiento en la Universidad de Chile. Santiago de Chile: Imprenta de la Opinión.

SebBa, Mark. 2007. Spelling and society: the Culture and Politics of Orthography Around the World. Cambridge: Cambridge University Press.

Serrano, Sol, Macarena Ponce de León y Francisca Rengifo. 2012. Historia de la educación en Chile (1810-2010). Tomo I, Aprender a leer y escribir (1810-2010). Santiago: Taurus.

SuÁReZ, José B. 1858. Prontuario de ortografia castellana. Santiago: Imprenta del Conservador [En línea]. Disponible en: http://www.memoriachilena.cl/archivos2/pdfs/MC0055757. pdf [Consulta 04/09/2015].

1886 [1865]. Prontuario de ortografía práctica. Valparaiso: Librería el Mercurio.

Subercaseaux, Bernardo. 2010. Historia de las ideas y de la cultura en Chile. Tomo IV, Nacionalismo y cultura. Santiago: Editorial Universitaria.

Torrejón, Alfredo. 1989. Andrés Bello, Domingo Faustino Sarmiento y el castellano de Chile. Thesaurus XLIV (3): 534-558.

Valdivia Castro, Carlos. 1933. Rápida mirada al panorama de la obra del $1^{\circ}$ preceptor primario y escritor didáctico Don José Bernardo Suárez. Santiago: Sociedad profesores de instrucción primaria.

Vargas Fontecilla, Francisco. 1854 [1857]. Lecciones de ortografia castellana. Madrid: Imprenta de la América.

VellemAn, BARRY L. 2014. Bello y las "escrituras disciplinarias": diccionarios, gramáticas, ortografías. Boletín de Filología XLIX (1): 179-192 [En línea]. Disponible en: http:// www.boletinfilologia.uchile.cl/index.php/BDF/article/viewFile/32440/34233 [Consulta 23/08/2015]. 